GHANA JOURNAL OF DEPARTMENT OF HEALTH, PHYSICAL EDUCATION AND RECREATION, SPORTS AND DANCE (GJOHPERSD)

Volume 7 \& 8, Year 2014 \& 2015

A JOURNAL OF THE DEPARTMENT OF HEALTH, PHYSICAL EDUCATION AND RECREATION (HPER)

UNIVERSITY OF CAPE COAST

GHANA, WEST AFRICA 


\title{
Analysis of Cardiorespiratory Fitness of 9-11 year Old Primary School Children in Nigeria Using Blood Pressure and Vital Capacity
}

\author{
Babalola, Joseph Folorunso \& Nna, Charity Chidinma \\ Corresponding author Department of Health, Physical Education \\ and Recreation, University of Cape Coast, Ghana
}

\begin{abstract}
The skeletal muscle has the ability to extract and use oxygen for generation of energy to perform physical activities. This ability is referred to as cardiorespiratory fitness. The variables measured in this study were resting systolic and diastolic blood pressure, vital capacity and forced vital capacity. Four hypotheses tested at 0.05 alpha level. There were significant differences between the participants and the standard norms in all the variables studied in this research. Resting systolic blood pressure $(t-C a l=190.576>t$ Crit. $=2.021, \quad P<0.05) ; \quad$ Resting diastolic blood pressure $(t-$ Cal $=51.951>t$-Crit. $=2.01, P<0.05)$; Vital Capacity $(t-C a l=-$ $31.527>t$-Crit. $=2.021, P<0.05) ;$ Forced Vital Capacity $(t-$ Cal=13.951 >t-Crit. $=2.021, P<0.05) ;$ Generally, it was observed that the cardiorespiratory fitness level of the participants was low despite the significant difference in the variables when compared to the standard norm. A programme should be designed to encourage children to lose weight in a healthy manner, thus reducing their BMI and improve their physical fitness, and general wellbeing. Parents should guide the pupils to spend less time on computer games and encourage active physical exercises in form of trekking to school where possible, in order to enhance their cardiorespiratory fitness.
\end{abstract}

Keywords: Cardiorespiratory fitness, Primary school children, Blood pressure 


\section{Introduction}

Cardiorespiratory fitness also known as cardiopulmonary fitness is a health-related component of physical fitness that measures the ability of the heart to pump blood and the ability of the skeletal muscle to extract and use oxygen. It is a condition when the heart, through the blood vessels, and respiratory system are able to supply the working muscles with oxygen and nutrients. The performance of the heart indicates the state of an individual's cardiovascular system functionality. Therefore, cardiorespiratory fitness is a measure of how well the body is able to transport oxygen to the working muscles during prolonged exercise. McArdle, Katch and Katch, (2000) said that cardiorespiratory fitness shows how well the muscles are able to absorb and use the oxygen, once it has been delivered, to generate adenosine triphosphate (ATP) which is the energy source, via cellular respiration. Indices of cardiorespiratory fitness include Systolic and Diastolic Blood Pressure, Mean Arterial Blood Pressure, Heart Rate, Respiratory Rate, Vital Capacity, Peak Expiratory Flow Rate and Maximum Oxygen Consumption (Ross \& Wilson, 2006).

Blood pressure is the pressure that blood exerts on the wall of the blood vessels. The pressure originates in the contraction of the heart, in turn, forcing blood out of the heart and into the blood vessels. The force is caused by the pumping action of the heart which sends blood to all parts of the body, through the arteries (McGlynn, 1999; McArdle et al., 2000). Blood pressure is affected by exercise in that it rises during sports performance which may be due to an increase in stroke volume and heart rate brought about by nervous and hormonal influences (Heyward, 2002).

There are two mechanisms that take place in the heart. These are systole and diastole. Systole is the contraction of the heart chambers while diastole is the relaxation of the chambers. The normal blood pressure that is considered to be at a safe level is $120 / 80$. The figure 120 is measured through systole while the 80 accounts for diastole. The systolic pressure will show the pressure that the heart emits when blood is forced out of the heart while diastolic pressure is the pressure that the heart shows when it is 
Analysis of Cardiorespiratory Fitness of 9-11 year old Primary School Children in Nigeria using Blood Pressure and Vital Capacity

relaxing. This is the main mechanism by which blood pressure operates (Heyward, 2002).

Vital capacity refers to the maximum amount of air that a person is capable of expelling from the lungs after maximum inhalation. This is equal to the sum of inspiratory reserve volume, expiratory reserve volume and tidal volume. A person's vital capacity can be measured using a regular or wet spirometer. Measurement of vital capacity can help the physician to determine if a patient is suffering from any underlying lung disease. Researches have found that exercises can help to increase vital capacity while smoking decreases it (Pollock et al., 1998; Adegoke \& Arogundade, 2002; Fabunmi, 2011). The measurement of vital capacity in an adult can show a value of between 3 and 5 liters. Demographic factors that can affect an individual's vital capacity are height, weight, sex, age and ethnicity. A low vital capacity is associated with a disability, obesity or chronic respiratory disease (Freedman, Dietz, Srinivasan, \& Berenson, 2004).

There seems to be very few studies on the fitness levels of children in Nigeria. There are also few indigenous studies with particular reference to cardiorespiratory fitness of primary school children. Most previous research efforts in Nigeria have concentrated on cardiorespiratory fitness of athletes and adult sedentary individuals (Adegoke \& Arogundade, 2002; Fabunmi, 2011). Many of the pupils within the age bracket of this study (911 years) prefer to play computer games instead of engaging in physical exercises. Some are chauffeur driven to school in their parents' cars, many of them use taxi cabs or motor cycles thus making them sedentary and with little or no opportunity for physical activities.

\section{Methodology}

Ex-post facto research design was used for this study. Measurements of resting systolic and diastolic blood pressure, vital capacity and forced vital capacity were taken using standardized instruments that were valid and reliable. The nature, purpose and procedure of the research were explained to the participants in 
detail. Written informed consent was also obtained from the prospective participants' teachers/parents prior to data collection.

Blood Pressure: The blood pressure was measured using sphygmomanometer and stethoscope. At the arrival at the venue of study, each participant was made to be in sitting position and be allowed to rest for 5 minutes before commencement of the measurement. The participant sat on a chair, while the left arm freed from clothing was positioned so that the brachial artery (at the antecubital crease) was held at heart level, roughly at the junction of the $4^{\text {th }}$ intercostals space with the sternum. The cuff of the sphygmomanometer was then wrapped around the left arm about 2.5 centimeters above the antecubital crease (Amusa, Igbanugo \& Toriola, 1998). The sphygmomanometer was inflated and gradually deflated during which the resting systolic and diastolic blood pressure was taken and recorded.

Vital capacity: The participant while in erect position was instructed to take a deep breath to fill the lung as much as possible and then place his/her lips over the end of the spirometer tube, to form an air tight seal and exhale as quickly as possible, blowing (Thomas \& Nelson, 2001). This was repeated 3 times. The values of vital capacity were read on the spirometer.

Forced Vital Capacity (FVC): In erect position, the participants were required to make a maximal inspiratory effort with lips tightly closed around the mouthpiece of the portable spirometer and exhale forcefully and continuously through the mouthpiece into the Spirometer. The values of the forced vital capacity were read on the spirometer.

\section{Results}

Data were analysed using one sample t-test to compare the obtained values with the existing standard norms and independent t-test to compare the participants by gender all at 0.05 level of significance. 
Analysis of Cardiorespiratory Fitness of 9-11 year old Primary School Children in Nigeria using Blood Pressure and Vital Capacity

Table 1: Percentage Age Distribution of the Participants

\begin{tabular}{|c|c|c|c|c|c|c|}
\hline & \multicolumn{2}{|c|}{ Boys } & \multicolumn{2}{|c|}{ Girls } & & \\
\hline Age in & No & $\%$ & No & $\%$ & Total & $\%$ \\
\hline years & 13 & 52 & 15 & 60 & 28 & 56 \\
\hline 9 & 8 & 32 & 6 & 24 & 14 & 28 \\
\hline 10 & 4 & 16 & 4 & 16 & 8 & 16 \\
\hline 11 & 25 & & 25 & & 50 & $100 \%$ \\
\hline
\end{tabular}

The table 1 above shows the percentage age distribution of the participants. Twenty eight representing $(56 \%)$ of participants were nine years old comprising of 13 boys and 15 girls. Fourteen of them were 10 years old, making 28 percent while eight participants were 11 years old making 16 percent. This shows that respondents with age of 9 years have the highest percentage.

Table 2: Gender Distribution of the Participants

\begin{tabular}{lll}
\hline Sex & No & Percentage \% \\
\hline Male & 25 & $50 \%$ \\
Female & 25 & $50 \%$ \\
Total & 50 & $100 \%$
\end{tabular}

Table 2 shows the gender distribution of the participants. The table shows that 25 participants or $50 \%$ were boys and 25 participants or $50 \%$ were girls. This implies that equal percentage of sex was used for the study. 
Table 3: Summary of the t-test statistics on Cardiorespiratory Fitness between the male and female Primary School Pupils.

\begin{tabular}{|c|c|c|c|c|c|c|c|c|c|}
\hline Variable & Gender & $\mathbf{N}$ & Mean & $\begin{array}{l}\text { Std. } \\
\text { Dev. }\end{array}$ & $\begin{array}{l}\text { Crit.- } \\
\text { t }\end{array}$ & $\begin{array}{l}\text { Cal.- } \\
\text { t }\end{array}$ & df & $\begin{array}{l}\text { Sig. } \\
(2 \\
\text { tail) }\end{array}$ & Remark \\
\hline \multirow[t]{2}{*}{ RSBP } & Male & 25 & 101.2000 & 5.2599 & \multirow[b]{2}{*}{2.00} & \multirow[b]{2}{*}{.336} & \multirow[b]{2}{*}{49} & \multirow[b]{2}{*}{.738} & \multirow[b]{2}{*}{ NS } \\
\hline & Female & 25 & 100.8000 & 2.7689 & & & & & \\
\hline \multirow[t]{2}{*}{ RDBP } & Male & 25 & 71.6000 & 6.2450 & \multirow[b]{2}{*}{2.00} & \multirow[b]{2}{*}{.993} & \multirow[b]{2}{*}{49} & \multirow[b]{2}{*}{.326} & \multirow[b]{2}{*}{ NS } \\
\hline & Female & 25 & 73.4000 & 6.5701 & & & & & \\
\hline \multirow[t]{2}{*}{$\mathrm{VC}$} & Male & 25 & .2336 & .1531 & \multirow[t]{2}{*}{2.00} & \multirow[t]{2}{*}{.126} & \multirow[t]{2}{*}{49} & \multirow[t]{2}{*}{.900} & \multirow[t]{2}{*}{ NS } \\
\hline & Female & 25 & .2236 & .1816 & & & & & \\
\hline \multirow[t]{2}{*}{ FVC } & Male & 25 & .3660 & .1881 & \multirow{2}{*}{2.00} & \multirow{2}{*}{.166} & \multirow{2}{*}{49} & \multirow{2}{*}{.860} & \\
\hline & Female & 25 & .3836 & .1846 & & & & & \\
\hline
\end{tabular}

\footnotetext{
Keys

RSBP

Resting Systolic Blood Pressure

RDBP

Resting Diastolic Blood Pressure

$\mathrm{VC}$

Vital Capacity

FVC

Forced Vital Capacity

A critical view of the Table 3 shows that there were no significant differences in the Cardiorespiratory Fitness between the male and female participants of this study. However, for hypotheses testing, when the two sexes were combined and the values were compared to the standard norms there were significant differences in the variables of study as shown in Table 4.
} 
Analysis of Cardiorespiratory Fitness of 9-11 year old Primary School Children in Nigeria using Blood Pressure and Vital Capacity

Table 4: Summary of the t-test statistics on Cardiorespiratory Fitness of Primary School Pupils Compared to Standard Norms

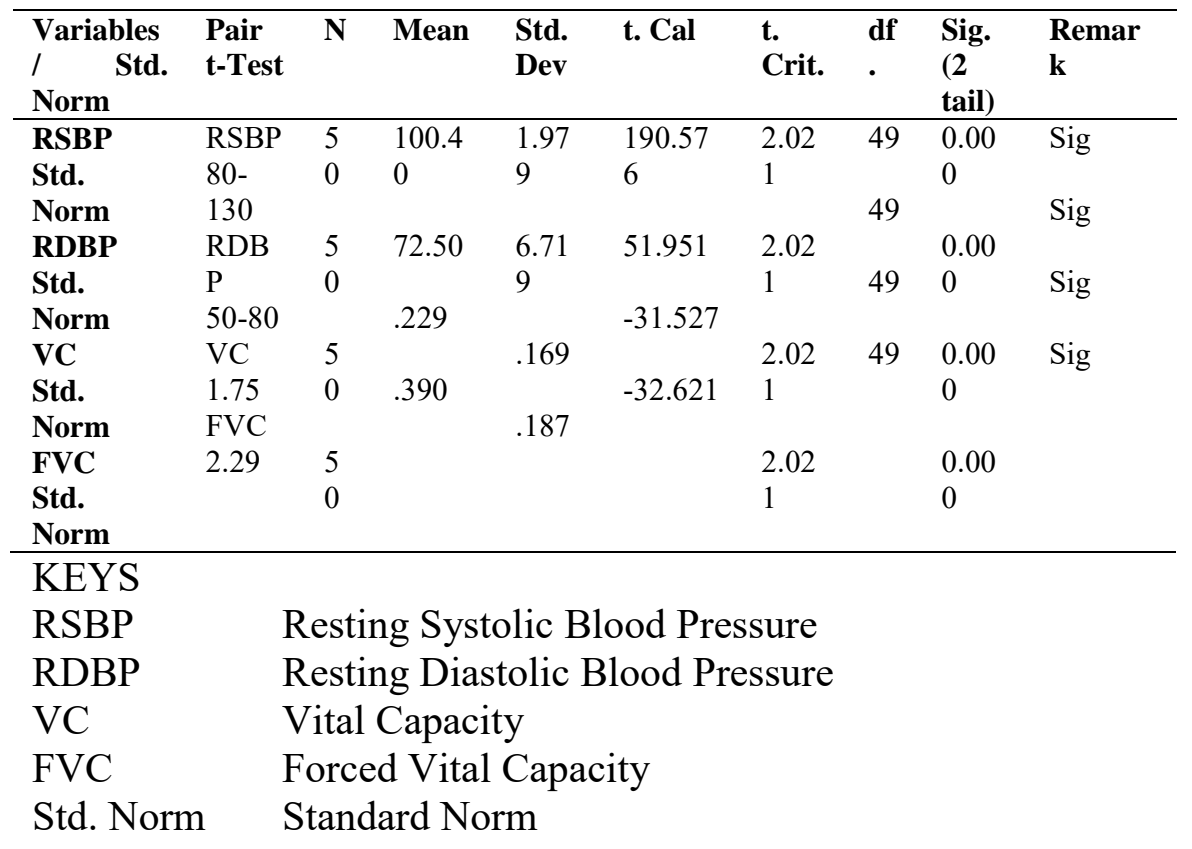

\section{Hypothesis 1}

Ho:- There will be no significant difference in the resting systolic blood pressure of male and female 9 to 11 years old primary school pupils when compared to standard norm.

Table 4 shows that there is a statistical significant difference in the resting systolic blood pressure of male and female 9 to 11 years old primary school pupils when compared to the Standard Norm. It was observed that the t- Calculated value was greater than $\mathrm{t}$-Critical value $(\mathrm{t}-\mathrm{Cal}=190.576>\mathrm{t}$-Crit. $=2.021$, $p<0.05)$. This shows that there was significant difference. The null hypothesis one was rejected. Therefore it was concluded that, there is a significant difference in the resting systolic blood pressure of male and female 9 to 11 years old primary school pupils when compared to the standard norm. 


\section{Hypothesis 2}

Ho:- There will be no significant difference in the resting diastolic blood pressure of male and female 9 to 11 years old primary school pupils when compared to standard norm.

Table 4 shows that there is a statistical significant difference in the resting diastolic blood pressure of male and female 9 to 11 years old primary school pupils when compared to the Standard Norm. It was observed that the t-Calculated value was greater than $\mathrm{t}$-Critical values $(\mathrm{t}-\mathrm{Cal}=51.951>\mathrm{t}$-Crit. $=2.01$, $\mathrm{P}<0.05$ ). This shows that there was a significant difference. The null hypothesis two was rejected. Therefore it was concluded that, there is a significant difference in the resting diastolic blood pressure of male and female 9 to 11 years old primary school pupils when compared to the standard Norm.

\section{Hypothesis 3}

Ho:- There will be no significant difference in the Vital Capacity of male and female 9 to 11 years old primary school pupils when compared to standard norm.

Table 4 shows that there is a statistical significant difference in the Vital Capacity of male and female 9 to 11 years old primary school pupils when compared to the Standard Norm. It was observed that the $\mathrm{t}$ - Calculated value was greater than $\mathrm{t}$ Critical values $(\mathrm{t}-\mathrm{Cal}=-31.527>\mathrm{t}$-Crit. $=2.021, \mathrm{P}<0.05)$. This shows that there was a significant difference. The null hypothesis three was rejected. Therefore it was concluded that, there is a significant difference in the Vital Capacity of male and female 9 to 11 years old primary school pupils when compared to the Standard Norm.

\section{Hypothesis 4}

Ho:- There will be no significant difference in the Forced Vital Capacity of male and female 9 to 11 years old primary school pupils when compared to the standard norm.

Table 4 shows that there is statistical significant difference in the Forced Vital Capacity of male and female 9 to 11 years old primary school pupils when compared to the Standard Norm. It 75 A Journal of the Department of Health, Physical Education and Recreation 
Analysis of Cardiorespiratory Fitness of 9-11 year old Primary School Children in Nigeria using Blood Pressure and Vital Capacity

was observed that the $\mathrm{t}$ - Calculated value was greater than $\mathrm{t}$ Critical values $(\mathrm{t}-\mathrm{Cal}=-32.621>\mathrm{t}-\mathrm{Crit} .=2.021, \mathrm{P}<0.05)$. This shows that there was significant difference. The null hypothesis four was rejected. Therefore it was concluded that, there is a significant difference in the Forced Vital Capacity of male and female 9 to 11 years old primary school pupils when compared to the standard norm.

\section{Discussion \\ Blood pressure}

What is considered to be normal blood pressure in children depends on factors such as height, age and sex. The biggest factor in children in this study is their height; taller kids have higher normal blood pressure than shorter kids. Stratton et al., (2007) noted that it is normal for children's blood pressure to change as they get older, and grow taller.

The mean systolic blood pressure in the male participants was $100.40 \pm 1.979$ while the mean diastolic blood pressure for the male and female participants was $72.50 \pm 6.719$ respectively. Literature shows that for children in age 9 categories, the upper and lower limits of normal average systolic pressure ranges between 113-121 and 114-120 while upper and lower limits of normal average diastolic pressure ranges between 76-81 and 75-79. The result of this study was in congruence with these values. The values of the normal average range for children in ages 10 and 11 as recorded in literature were also in consonance with the values recorded for this study (Appendix 1).

The Low-Normal Pediatric Systolic Blood Pressure for children of school-age (6-12 years) is greater than 80 (Appendix 2). The average resting systolic blood pressure for the children in this study was $95 \mathrm{mmHg}$. Blair, Kampert \& Kohl, (1996), and Vincent (2014) stated that school aged children (6-12 years) have systolic blood pressure of 85-120 and diastolic blood pressure of $50-80 \mathrm{mmHg}$. The statistical analysis shows that there was a significant difference in the resting systolic blood pressure of male and female 9 to 11 years old primary school pupils used in A Journal of the Department of Health, Physical Education and Recreation 76 
Babalola et al

this study, when compared to 80-130 and 50-80 which are the standard norms for Systolic Blood Pressure and diastolic blood pressure respectively.

\section{Vital capacity}

The vital capacity of the lungs is the volume of air which can be expelled after the deepest possible inhalation. The mean value for the participants in this study was $0.229 \pm 0.169$. Thomas and Nelson (2001) reported that the normal range of vital capacity for a given height is estimated on the basis of these observations to be given by the equation $\mathrm{y}=-2.41+0.0341 \mathrm{x} \pm 2(0.199)$, where $\mathrm{y}$ $=$ vital capacity in liters, and $\mathrm{x}=$ standing height in $\mathrm{cm}$. The $\mathrm{t}$ Calculated value was greater than $\mathrm{t}$-Critical values $(\mathrm{t}-\mathrm{Cal}=-31.527<$ $\mathrm{t}$-Crit. $=2.021),(\mathrm{P}<0.05)$. This shows that there was a significant difference when the values were compared with the standard norm. Also, significant difference was reported for forced vital capacity (table 4).

\section{Conclusion}

The results show that there were significant differences between the participants and the standard norms in all the variables studied. The reason may be attributed to the developmental stage of the pupils. Finings revealed significant difference between the cardiorespiratory fitness levels of the participants when compared to the standard norm. This may result from the low level of the pupils' participation in programmed physical activities as most of them indulged in computer games instead of real physical activities.

Generally speaking, the physical fitness levels among school children have been falling leading to poor cardiorespiratory fitness. Many school children do not engage in physical exercises. This may be because of the lack of availability of qualified physical education teachers among the school staff or as a result of the lazy attitude of the few qualified physical education teachers available. 
Analysis of Cardiorespiratory Fitness of 9-11 year old Primary School Children in Nigeria using Blood Pressure and Vital Capacity

\section{Recommendation}

It was recommended that qualified physical education teachers should be employed in the primary schools to handle the course and guide the pupils during outdoor physical education classes.

\section{References}

Adegoke, O.A. and Arogundade, O. 2002. The effects of chronic exercise on lung function and basal metabolic rate in some Nigerian athletes. African Journal of Biomedical Research 5 pp 9-11

Amusa, L.O., Igbanugo, V.C. and Toriola, A.L. 1998. Experiments and laboratory experiences in exercise physiology $\left(2^{\text {nd }}\right.$ ed.) Nigeria Lab Publication Limited.

Andersen, L.B., Wedderkopp, N., Hansen, H.S., Cooper, A.R. and Froberg, K. 2003. Biological cardiovascular risk factors cluster in Danish children and adolescents: The European Youth Heart Study. Prev Med. 37(4): 363-367.

Blair, S.N, Kampert, J.B. and Kohl H.W. 1996. Influences of cardiorespiratory fitness and other precursors on cardiovascular disease and all-cause mortality in men and women. JAMA; 276(3):205-210

Bryman, M. A. 2001. Fitness and wellness for life. (7th ed.) Boston, WCB McGraw Hill Book

Chad, T. 2001. Cardio-vascular exercise principles and guidelines. Brian Barton jumpsite www.empiregym.net retrieved $14 / 07 / 2014$

Church, T.S., Kampert, J.B., Gibbons, L.W. and Barlow, C.E. 2001. Usefulness of cardiorespiratory fitness as a predictor of all-cause and cardiovascular disease mortality in men with systemic hypertension. Am $J$ Cardiol. 88(6):651-656

Dunn, A. Marcus, B. and Kampert, K. 1997. Reduction of cardiorespiratory disease risk factors: 6 month results from Project active preventive medicine. 26: 883-892. 
Fabunmi, A.A. 2011. Comparative effects of a twelve-week aerobic exercise programme on respiratory functions of obese and non-obese sedentary individuals in Ibadan, Nigeria. Unpublished Ph.D Thesis. Department of Human Kinetics and Health Education, University of Ibadan, Ibadan.

Freedman, D.S., Dietz, W.H., Srinivasan, S.R. and Berenson, G.S. 2004. The relation of overweight to cardiovascular risk factors among children and adolescents: The Bogalusa Heart Study. Pediatrics. 103:1175-1182.

Heyward, V.H. 2002. Advanced fitness assessment and exercise prescription $\left(4^{\text {th }}\right.$ ed) USA Human Kinetics.

Klabunde, R.E. 2005. Cardiovascular Physiology Concepts. Lippincott Williams \& Wilkins. pp. 93-4.

McArdle, D.M., Katch, F.I. and Katch, V.L. 2000. Essentials of exercise physiology. $2^{\text {nd }}$ ed. Philadelphia PA: Lippincott Williams and Wilkins.

McGlynn, G. 1999. Dynamics of Fitness: A Practical Approach. $5^{\text {th }}$ ed. St. Louis. The McGraw-Hall Companies Inc.

Pollock, M.C., Gaesser, G.A., Butcher, J.D., Despires, J.P., Dishman, R.K., Frankline, B.A. and Garber, C.E. 1998. Quality and Quantity of exercise for developing and maintaining cardio-respiratory and Muscular fitness and flexibility in healthy adults. Med. Sci. Sports Exercise 30:79-97

Ross. W. and Wilson, G. 2006. Anatomy and physiology in health and illness. UK: Churchill Livingstone.

Thomas, J.R. and Nelson, J.K. 2001. Research methods in physical activity $\left(4^{\text {th }}\right.$ ed). United state of America. Human Kinetics.

Vincent, I. (2014) Range of Heart Rate for Children and Teens http://pediatrics.about.com/od/pediatricadvice/a/NormalPulse-Rates-For-Kids.htm Retrieved 13/01/2015)

Wedderkopp, N., Froberg, K., Hansen, H.S. and Andersen, L.B. 2004. Secular trends in physical fitness and obesity in Danish 9-year-old girls and boys: Odense School Child 
Analysis of Cardiorespiratory Fitness of 9-11 year old Primary School Children in Nigeria using Blood Pressure and Vital Capacity

Study and Danish substudy of the European Youth Heart Study. Scand J Med Sci Sports. 14(3): 150-155.

\section{APPENDIX}

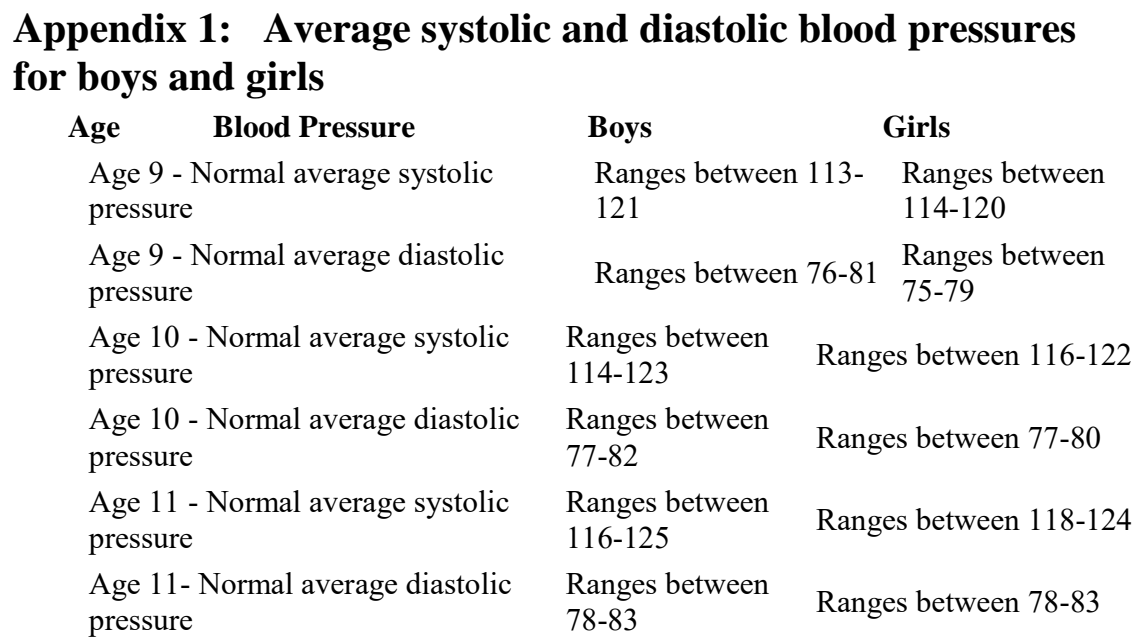

(Adapted from http://www.md-health.com/Normal-Blood-Pressure-ForChildren.html)

\section{Appendix 2: Low-Normal Pediatric Systolic Blood Pressure Age* Low Normal \\ Infant (birth-1 year) greater than $60^{*}$ \\ Toddler (1-3 years) greater than $70^{*}$ \\ Preschooler (3-6 years) greater than 75 \\ School-age (6-12 years) greater than 80 Adolescent (12-18 years) greater than 90}

(https://www.health.ny.gov/professionals/e) 